Research Article

\title{
Physical Activity, Obesity, and Hypertension among Adults in a Rapidly Urbanised City
}

\author{
Qianqian Dun, ${ }^{1}$ Wanglin Xu, ${ }^{1}$ Maozhen Fu, ${ }^{2}$ Nengjian $W u,{ }^{2}$ Justin B. Moore, ${ }^{3}$ Ting Yu, \\ Xin Li, ${ }^{4}$ Yating Du, ${ }^{1}$ Biao Zhang, ${ }^{1}$ Qiaomai Wang, ${ }^{1}$ Yiting Duan, ${ }^{1}$ Ziqi Meng, \\ Shuangshuang Tian, ${ }^{1}$ and Yuliang Zou $\mathbb{1}^{1}$ \\ ${ }^{1}$ School of Health Sciences, Wuhan University, Wuhan, Hubei 430071, China \\ ${ }^{2}$ Disease Control and Prevention Center of Pingshan District in Shenzhen City, Guangzhou 518100, China \\ ${ }^{3}$ Department of Implementation Science, Wake Forest School of Medicine, Medical Center Boulevard, Winston-Salem, \\ NC 27157, USA \\ ${ }^{4}$ School of Urban Design, Wuhan University, Wuhan, Hubei 430072, China \\ ${ }^{5}$ School of Nursing, Weifang Medical University, Weifang, Shandong 261053, China \\ Correspondence should be addressed to Yuliang Zou; zouyl@whu.edu.cn
}

Received 9 March 2021; Revised 17 June 2021; Accepted 3 August 2021; Published 12 August 2021

Academic Editor: Massimo Salvetti

Copyright ( 2021 Qianqian Dun et al. This is an open access article distributed under the Creative Commons Attribution License, which permits unrestricted use, distribution, and reproduction in any medium, provided the original work is properly cited.

\begin{abstract}
Background. Few studies have explored the relationship between the level of physical activity and the occurrence or prevalence of obesity and hypertension among people residing in urbanised areas. Method. A cross-sectional study involving a sample of 1,001 adults was conducted. Descriptive statistics were used to describe sociodemographic variables, physical activity levels, body mass index (BMI), and prevalence of hypertension. Logistic regression models were adopted to investigate the relationship between these factors. Results. A total of 939 respondents who provided valid responses were included. Among them, 56.5\% of the participants reported engaging in high levels of physical activity. However, $40.4 \%$ of the respondents were classified as overweight or obese, and $31.9 \%$ had diagnosed hypertension. After adjusting for sociodemographic factors, logistic regression analysis revealed that physical activity levels were negatively correlated with the prevalence of BMI $(\mathrm{OR}=0.564,95 \% \mathrm{CI}$ : $0.352-0.905$; $\mathrm{OR}=0.583,95 \% \mathrm{CI}: 0.375-0.907)$ and hypertension ( $\mathrm{OR}=0.556,95 \% \mathrm{CI}: 0.348-0.888)$. Conclusions. Our study confirms recent evidence regarding the amount of physical activity that is associated with lower prevalence of obesity and hypertension in Pingshan District. Furthermore, different physical activities of various intensity levels had different effects on hypertension. Residents should be encouraged to engage in physical activities and maintain a healthy weight to improve their quality of life.
\end{abstract}

\section{Introduction}

Hypertension, also known as elevated blood pressure (BP), is a disease that occurs when blood vessels are constantly strained by high pressure [1]. Over $90 \%$ of patients with hypertension of unknown causes are diagnosed with primary hypertension. By contrast, $5 \%-10 \%$ of patients with hypertension suffer from other diseases, a condition called secondary hypertension. Hypertension is the most common cardiovascular disease (CVD) in China and a major public health problem worldwide [2]. According to the 2015 report on the status of "Nutrition and Chronic Diseases of Chinese Residents," the prevalence of hypertension among adults in
China was $25.2 \%$, and the prevalence of this disease in urban areas $(26.8 \%)$ was higher than that in rural areas (23.5\%). Moreover, the prevalence was higher in men than in women, and it notably increased with age [3]. According to the Sixth National Census (2010), the number of patients with hypertension in China was estimated to be 270 million [4]. In 2013, the direct economic burden caused by hypertension accounted for $6.6 \%$ of the total health costs in the country [5].

With rapid urbanisation and ageing in China, the prevalence of hypertension is increasing, thereby imposing a serious economic and disease burden to society [6]. Numerous studies reported that high BP increases the risk of 
developing common chronic diseases, such as heart, brain, and kidney diseases, as well as the occurrence of cerebrovascular accidents and coronary heart disease; moreover, hypertension negatively affects the health of pregnant women and newborn children [7-10]. Perumareddi [11] demonstrated that hypertension is clinically associated with the risks of CVDs, three arteriosclerotic diseases, and other complications, such as congestive heart failure and cerebrovascular diseases. Ettehad et al. [12] argued that lowering BP can effectively prevent CVDs and death. Therefore, the occurrence and development of hypertension must be prevented and controlled to reduce the risk of CVDs and cerebrovascular diseases.

Hypertension is a disease caused by a combination of multiple factors. Gene-gene, gene-environment, and environment-environment interactions lead to different populations and individuals at different risk of developing hypertension [13]. Current studies proposed that the incidence of hypertension involves two main aspects: one is genetic, that is, individuals having different levels of genetic susceptibility, and the other is environmental $[14,15]$. From a social ecological perspective [16], individual behaviour is strongly correlated with hypertension because physical activity (or the lack of it) and dietary intake determine if a person will develop obesity [17]. Furthermore, overweight and obesity are important risk factors affecting the incidence of hypertension [18]. You et al. [19] showed that even $10 \mathrm{~min}$ of vigorous physical activity every week can help reduce the prevalence of hypertension. Several studies abroad and in the country have examined the relationship between physical activity and hypertension [19-22].

With the development of society and the introduction of health policies, people pay more attention to health. At the same time, the urbanisation process began in the late 1970s and has dramatically increased its pace during the past two decades [23]. Rapid urbanisation has posed additional challenges to the population, who has to deal with the double threats of worsening/unhealthy diets due to increasing availability of unhealthy foods and decreasing physical activity due to exponential growth in car ownership and use. Therefore, the relationship between physical activity and prevalence of hypertension in this context must be examined.

In addition, the research area is Pingshan District, with an area of $168 \mathrm{~km}^{2}$, located in the northeast of Shenzhen City, Guangdong Province in southern China. This manufacturingdominated region started urbanising in 2004, providing housing for hundreds of thousands of migrant workers. As a major residential area for migrant workers, the age distribution is positively skewed, and thus morbidity and mortality rates due to chronic diseases in this area are lower than those in other regions. However, the threat posed by unhealthy lifestyles remains high and may lead to higher prevalence of chronic diseases, such as obesity and hypertension. This is a young migrant population and a unique opportunity to study the impact of urbanisation on hypertension, PA, and obesity.

The aim of this study was to examine the relationship between physical activity and prevalence of obesity and hypertension in rapidly urbanising areas in the context of the "healthy city projects" of China. This study provides important insights into the burden of hypertension epidemic in relation to obesity due to the lack of physical activity in the population in urban areas. Moreover, this study offers guidance for formulating science-based strategies for hypertension prevention and control in Pingshan District. In future research, large-scale public health interventions on physical activity and obesity can be developed and tested.

\section{Methods}

2.1. Study Design and Sampling. A three-stage, stratified sampling strategy was employed. Six of the 16 communities in Pingshan District were randomly selected. From each sampled community, 150 families were selected. Finally, one member from each family between the age of 18 and 69 years was randomly selected via the Kish Grid sampling (one qualified subject from each family based on the principle of equal probability) [24]. A total of 1,001 adults were surveyed. Sixty-two questionnaires were excluded from the analysis due to missing data on key variables, resulting in a final sample of 939 respondents.

Various sociodemographic and physical information, such as gender, age, length of residency, education level, occupation, marital status, physical activity, and BMI (weight divided by the square of height), were collected through the questionnaires.

2.2. Assessment of Physical Activity. Self-reported data on physical activity during an entire week were collected via the long form International Physical Activity Questionnaire [25]. Data were collected from specific settings across several domains, including occupation, transportation, housework, and recreational activity, and reported in metabolic equivalents of task $($ MET $) \times$ minutes per week. MET is a physiological measure expressing the energy cost of physical activities, and it is defined as the ratio of metabolic rate (and therefore the rate of energy consumption) during a specific physical activity to a reference metabolic rate [26]. Walking MET was assigned with a ratio of 3.3 , moderate-intensity activity with a ratio of 4.0 , and high-intensity activity with a ratio of 8.0. Physical activity was calculated using the formula $($ MET $-\min )=$ MET $\times$ activity days per week $(d) \times$ daily activity time ( $\mathrm{min})$.

According to the total physical activity and the frequency of different types of physical activities within 1 week, physical activity was categorised into high, medium, and low [27]. High level satisfied guidelines for vigorous physical activity ( $\geq$ three times per week, $\geq 1500$ METS) or various physical activities ( $\geq$ seven times per week, $\geq 3000$ METS). Moderate level satisfied guidelines for vigorous physical activity ( $\geq$ three times per week, $\geq 20$ min per day), moderate physical activity/walking ( $\geq$ five times per week, $\geq 30 \mathrm{~min}$ per day), or various physical activities ( $\geq$ five times per week, $\geq 600$ METS). Low level comprised two types: insufficiently active (some physical activity but less than the criteria for high or moderate level) or inactive (no physical activity reported). 
2.3. BMI and BP Measurements. Objective anthropometric measures of body weight $(\mathrm{kg})$ and height $(\mathrm{m})$ were obtained from the study participants at home or through community visits. BMI was calculated as body weight in $\mathrm{kg}$ divided by height in meters squared and assigned to two categories: 1 , overweight or obese $(\mathrm{BMI} \geq 24)$; 0 , otherwise $(\mathrm{BMI}<24)$.

BP was measured following the 2018 Chinese guidelines for the management of hypertension: normal blood pressure ( $\mathrm{SBP}<120 \mathrm{mmHg}$ and $\mathrm{DBP}<80 \mathrm{mmHg}$ ); normal high values $(\mathrm{SBP}=120-139 \mathrm{mmHg}$ and $/$ or $\mathrm{DBP}=80-89 \mathrm{mmHg}$ ); hypertension ( $\mathrm{SBP} \geq 140 \mathrm{mmHg}$ and/or $\mathrm{DBP} \geq 90 \mathrm{mmHg}$ ) [28]. In brief, $\mathrm{BP}$ was measured twice or more by using a Mercury or automatic sphygmomanometer in a sitting position after a minimum of 5 min rest after the anthropometric measurements [18]. If the two readings of SBP or DBP differed by $5 \mathrm{mmHg}$, then the readings were measured again, and the average of the three readings was recorded [28].

2.4. Statistical Analysis. Data were analysed using SPSS for Windows software package version 20 and AMOS 20.0 (SPSS Inc., Chicago, Illinois). Frequency and percentage were utilised to describe the sociodemographic variables. Binary logistic regression was employed to examine the relationship between physical activity, obesity, and hypertension. Age, gender, education level, occupation, marital status, smoking history, drinking history, and family history of hypertension were included within all regression models to account for any confounding effects of these factors. Significance was set at $p<0.05$.

\section{Result}

The mean age of the study population was 40.7 years $(\mathrm{SD}=12.2), 53.2 \%$ of which were women. Half of the participants were engaged in the first type of occupation, such as agriculture, production, business, and service personnel. In terms of education level, only $43.9 \%$ reached at least junior high school. Men accounted for $98.7 \%$ of those who smoke. Similarly, more men than women drank alcohol. Notably, $80.9 \%$ reported no family history of hypertension. Of the total sample, $11.3 \%$ reported engaging in low physical activity levels, $32.1 \%$ in moderate physical activity levels, and $56.5 \%$ in high physical activity levels. Among the participants, $40.4 \%$ were overweight or obese, and $31.9 \%$ were hypertensive (Table 1).

Chi-square analysis revealed a correlation between gender $\left(\chi^{2}=9.639, P=0.002\right)$, age $\left(\chi^{2}=21.085, P<0.001\right)$, education $\left(\chi^{2}=24.348, \quad P<0.001\right)$, and hypertension. Moreover, the analysis found a significant association between smoking behaviour and hypertension $\left(\chi^{2}=5.863\right.$, $P=0.015)$. Family history of hypertension was significantly associated with the prevalence of hypertension. Furthermore, the results showed a close relationship between obesity and hypertension (Table 2).

The results of multivariable analysis of the influence of physical activity on obesity and hypertension are summarised in Table 3. In model 1, after adjusting for basic demographic characteristics, such as gender, age, education, occupation type, marital status, and individual behaviour, the effect of moderate and high physical activity on obesity was statistically significant $(\mathrm{OR}=0.564, \quad 95 \% \quad \mathrm{CI}$ : $0.352-0.905 ;$ OR $=0.583,95 \%$ CI: 0.375-0.907). Model 2 revealed that the effect of high physical activity level on hypertension was statistically significant $(\mathrm{OR}=0.556,95 \%$ CI: 0.384-0.888).

The effect of the type of physical activity on hypertension is depicted in Figure 1. Women were more sensitive than men to the effects of physical activity. After adjusting for the influence of confounding factors, physical activity at work, housework, and leisure were related to the prevalence of hypertension unlike physical inactivity. After adjusting for the effects of confounding factors, the results revealed a significant association between obesity and hypertension $(\mathrm{OR}=0.700,95 \%$ CI: 0.514-0.953) (Table 4).

After adjusting for confounding factors, such as gender, age, education level, marital status, smoking history, and drinking history, multivariable unconditional logistic regression analysis revealed that people with no hypertension family history with overweight/obesity were $58.5 \%$ less likely to have hypertension $(\mathrm{OR}=0.415,95 \% \mathrm{CI}=0.229-0.752)$ (Table 5).

\section{Discussion}

This study explored the relationship between physical activity and obesity and hypertension in the population in Pingshan District, Shenzhen City, China. Even after adjusting the sociodemographic characteristics of the respondents, a statistically significant difference was observed between the residents' physical activity levels and risk of obesity. Moderate and high physical activity levels were negatively correlated with the risk of obesity. The more active the residents were, the less likely they would be obese. Moreover, physical activity level was negatively correlated with the prevalence of hypertension, further verifying the protective effects of physical activity against hypertension $[22,29]$. Physical activity is usually recommended as an important lifestyle modification that may help in preventing hypertension [20]. Furthermore, after adjusting for sociodemographic variables, women were found to be more sensitive than men to the effects of physical activity. In the family, aside from engaging in work and leisure, women generally do the housework. Household activities may increase overall physical activity because they require physical exertion, such as cooking, shopping, and gardening [30]. In addition, as long as a certain exercise intensity is reached, whether it is aerobic or resistance training, it will cause a significant increase in the content of $\beta$-endorphin in the female central nervous system, promote adaptive changes in the hypothalamic-pituitary-ovarian axis, and promote oestrogen in the body secretion [31]. Oestrogen is an important hormone involved in the metabolism of substances and energy in the body. Studies have found that the reduction of female oestrogen is closely related to the occurrence of abdominal obesity, insulin resistance, and related diseases [32]. However, moderate/vigorous physical activity cannot completely offset the increased risk of hypertension associated with overweight and obesity [33]. In general, the 
TABLE 1: Individual characteristics of study participants, overall and by gender.

\begin{tabular}{|c|c|c|c|c|c|c|c|}
\hline \multirow{2}{*}{ Variables } & \multicolumn{2}{|c|}{ All } & \multicolumn{2}{|c|}{ Male } & \multicolumn{2}{|c|}{ Female } & \multirow{2}{*}{$P$} \\
\hline & $n$ & $\%$ & $n$ & $\%$ & $n$ & $\%$ & \\
\hline Age (years) & & & & & & & 0.244 \\
\hline $18-29$ & 226 & 22.6 & 108 & 47.8 & 118 & 52.2 & \\
\hline $30-44$ & 374 & 37.4 & 187 & 50.0 & 187 & 50.0 & \\
\hline $45-59$ & 339 & 33.9 & 144 & 42.5 & 195 & 57.5 & \\
\hline$\geq 60$ & 62 & 6.2 & 29 & 46.8 & 33 & 53.2 & \\
\hline Educational level & & & & & & & $<0.001$ \\
\hline Primary school or below & 218 & 21.8 & 74 & 33.9 & 144 & 66.1 & \\
\hline Junior high school & 439 & 43.9 & 195 & 44.4 & 244 & 55.6 & \\
\hline High school and secondary school & 239 & 23.9 & 140 & 58.6 & 99 & 41.4 & \\
\hline College degree and above & 105 & 10.5 & 59 & 56.2 & 46 & 43.8 & \\
\hline Occupational status & & & & & & & 0.181 \\
\hline First category & 497 & 49.7 & 234 & 47.1 & 263 & 52.9 & \\
\hline Second category & 174 & 17.4 & 71 & 40.8 & 103 & 59.2 & \\
\hline Third category & 330 & 33.0 & 163 & 49.4 & 167 & 50.6 & \\
\hline Marital status & & & & & & & 0.002 \\
\hline Married & 851 & 85.0 & 415 & 48.8 & 436 & 51.2 & \\
\hline Unmarried & 150 & 15.0 & 53 & 35.3 & 97 & 64.7 & \\
\hline Smoking & & & & & & & $<0.001$ \\
\hline Yes & 224 & 22.4 & 221 & 98.7 & 3 & 1.3 & \\
\hline No & 775 & 77.6 & 246 & 31.7 & 529 & 68.3 & \\
\hline Drinking & & & & & & & $<0.001$ \\
\hline Yes & 150 & 15.1 & 133 & 88.7 & 17 & 11.3 & \\
\hline No & 845 & 84.9 & 333 & 39.4 & 512 & 60.6 & \\
\hline Family history of hypertension & & & & & & & 0.817 \\
\hline Yes & 189 & 19.1 & 90 & 47.6 & 99 & 52.4 & \\
\hline No & 799 & 80.9 & 373 & 46.7 & 426 & 53.3 & \\
\hline Physical activity level & & & & & & & 0.005 \\
\hline Low level & 111 & 11.3 & 56 & 50.5 & 55 & 49.5 & \\
\hline Moderate level & 315 & 32.1 & 123 & 39.0 & 192 & 61.0 & \\
\hline High level & 554 & 56.5 & 278 & 50.2 & 276 & 49.8 & \\
\hline Overweight or obesity & & & & & & & 0.839 \\
\hline No & 545 & 59.6 & 257 & 47.2 & 288 & 52.8 & \\
\hline Yes & 370 & 40.4 & 177 & 47.8 & 193 & 52.2 & \\
\hline Hypertension & & & & & & & 0.002 \\
\hline No & 639 & 68.1 & 280 & 43.8 & 359 & 56.2 & \\
\hline Yes & 300 & 31.9 & 164 & 54.7 & 136 & 45.3 & \\
\hline
\end{tabular}

First category: agriculture, forestry, animal husbandry, fishery, production, transportation equipment operations, business, and service personnel. Second category: state agencies, institutions, civil servants, professional and technical personnel, and students. Third category: unemployment, housework, and retired persons.

prevalence of hypertension in Pingshan District was 31.9\%, which is higher than that in Shenzhen City (19.04\%) and in the entire country $(25.2 \%)[3,34]$. Pingshan District is in the early stages of urbanisation, with factory manufacturing as the primary industry in the area. Since this is a key residential area for migrant workers, the age structure is skewed towards younger adults. However, they are less educated, lack health awareness with insufficient investment in health, and engage in unhealthy lifestyle [35]. These factors may lead to higher obesity and hypertension rates in Pingshan District than those in other regions.

These findings were similar to those reported in Nigeria [36]. Studies have found that overweight and obese people are less likely to suffer from hypertension. This does not mean that obesity is a protective factor, because this is a cross-sectional study that cannot confirm its causality. It can only be said that overweight and obese people should strive to become physically active because physical activity will help in achieving physical fitness and ideal weight as well as reduce the risk of hypertension due to obesity, or obese people should pay more attention to their health [37]. Moon et al. [38] suggested that individuals with less physical activity and more sedentary behaviour may be more susceptible to genetic effects on adiposity. From another perspective, individuals with a greater genetic predisposition to obesity are more susceptible to the beneficial effects of physical activity and the deleterious effects of sedentary behaviour on adiposity [38]. Previous studies proposed that redox imbalance might be associated with the pathogenesis of hypertension, although it may not be the only cause of BP elevation [39-41]. Interestingly, physical activity has been suggested to be helpful in reducing the risk of hypertension by improving the redox state, particularly in the vascular wall $[42,43]$. Therefore, aside from traditional pharmacological treatment modalities, physical exercise may 
TABLE 2: Univariate analysis of influencing factors of hypertension.

\begin{tabular}{|c|c|c|c|c|}
\hline \multirow{2}{*}{ Variables } & \multicolumn{2}{|c|}{ Hypertension } & \multirow{2}{*}{$\chi^{2}$} & \multirow{2}{*}{$P$} \\
\hline & Yes $(n(\%))$ & No $(n(\%))$ & & \\
\hline Gender & & & 9.639 & 0.002 \\
\hline Male & $164(54.7)$ & $280(43.8)$ & & \\
\hline Female & $136(45.3)$ & $359(56.2)$ & & \\
\hline Age (years) & & & 21.085 & $<0.001$ \\
\hline $18-29$ & $47(15.7)$ & $159(24.9)$ & & \\
\hline $30-44$ & $99(33.0)$ & $248(38.8)$ & & \\
\hline $45-59$ & $129(43.0)$ & $197(30.8)$ & & \\
\hline$\geq 60$ & $25(8.3)$ & $35(5.5)$ & & \\
\hline Educational level & & & 24.348 & $<0.001$ \\
\hline Primary school or below & $89(29.7)$ & $120(18.8)$ & & \\
\hline Junior high school & $137(45.7)$ & $273(42.7)$ & & \\
\hline High school and secondary school & $56(18.7)$ & $165(25.8)$ & & \\
\hline College degree and above & $18(6.0)$ & $81(12.7)$ & & \\
\hline Occupational status & & & 5.384 & 0.068 \\
\hline First category & $149(49.7)$ & $315(49.3)$ & & \\
\hline Second category & $63(21.0)$ & $100(15.6)$ & & \\
\hline Third category & $88(29.3)$ & $224(35.1)$ & & \\
\hline Marital status & & & 3.291 & 0.070 \\
\hline Married & $245(81.7)$ & $551(86.2)$ & & \\
\hline Unmarried & $55(18.3)$ & $88(13.8)$ & & \\
\hline Medical insurance & & & 5.648 & 0.130 \\
\hline No & $44(14.7)$ & $109(17.1)$ & & \\
\hline Others & $42(14.0)$ & $58(9.1)$ & & \\
\hline Medical insurance for urban residents/new rural cooperative medical insurance & $141(47.0)$ & $317(49.6)$ & & \\
\hline Medical insurance for urban employees & $73(24.3)$ & $155(24.3)$ & & \\
\hline Smoking & & & 5.863 & 0.015 \\
\hline Yes & $82(27.3)$ & $129(20.3)$ & & \\
\hline No & $218(72.7)$ & $508(79.7)$ & & \\
\hline Drinking & & & 1.228 & 0.268 \\
\hline Yes & $51(17.0)$ & $90(14.2)$ & & \\
\hline No & $249(83.0)$ & $543(85.8)$ & & \\
\hline Family history of hypertension & & & 16.401 & $<0.001$ \\
\hline Yes & $80(27.1)$ & $100(15.8)$ & & \\
\hline No & $215(72.9)$ & $532(84.2)$ & & \\
\hline Overweight or obesity & & & 7.878 & 0.005 \\
\hline Yes & $97(33.9)$ & $268(43.8)$ & & \\
\hline No & $189(66.1)$ & $344(56.2)$ & & \\
\hline Physical activity & & & 4.099 & 0.129 \\
\hline Low level & $42(14.4)$ & $65(10.4)$ & & \\
\hline Moderate level & $99(33.9)$ & $202(32.2)$ & & \\
\hline High level & $151(51.7)$ & $360(57.4)$ & & \\
\hline
\end{tabular}

be potentially important for preventing or treating hypertension or hypertension-related diseases [44]. These findings were similar to the results of the present study. People with more physical activity are less likely to be obese and develop hypertension. However, some studies believe that moderate exercise will enhance the body's immune function, while prolonged excessive exercise will cause the body to produce an "empty window period", in which Th1 and Th2 are unbalanced, the number of NK cells decreases, and the CD4 + /CD8 + ratio decreases. The function of lymphocytes is inhibited. Especially for people who sit for a long time, strenuous exercise for a long time is not a suitable exercise intensity, which can easily lead to suppression of immune function. The exercise process needs to be carried out step by step $[45,46]$.
The present study also proved that people with a family history of hypertension are more likely to develop hypertension. Other studies obtained similar results [47]. Although family history is uncontrollable, the risk of being overweight or developing obesity can be reduced within the normal range through exercise and healthy diet. Therefore, people in high-risk groups should exercise and consume a reasonably healthy diet to reduce the risk of hypertension.

Notably, the residents who were overweight or obese were found to be less likely to develop high BP than those who had normal weight. Several reasons may possibly explain this result. Previous studies found that family history of hypertension and being overweight/obesity have an interactive effect on hypertension [47]. Among the overweight/obese 
TABLE 3: Multivariable analysis of the effects of physical activity on overweight/obesity and hypertension.

\begin{tabular}{|c|c|c|c|c|}
\hline \multirow[t]{2}{*}{ Variables } & \multicolumn{2}{|c|}{$\begin{array}{l}\text { Overweight/obesity } \\
\text { (model 1) }\end{array}$} & \multicolumn{2}{|c|}{$\begin{array}{l}\text { Hypertension } \\
\text { (model 2) }\end{array}$} \\
\hline & OR & $95 \% \mathrm{CI}$ & OR & $95 \% \mathrm{CI}$ \\
\hline Gender (ref = "male") & 0.928 & $0.656-1.311$ & 0.525 & $0.360-0.764$ \\
\hline \multicolumn{5}{|l|}{ Age (years) (ref = "18-29") } \\
\hline $30-44$ & 1.173 & $0.807-1.704$ & 1.266 & $0.819-1.958$ \\
\hline $45-59$ & 0.842 & $0.563-1.259$ & 1.771 & $1.133-2.769$ \\
\hline$\geq 60$ & 0.788 & $0.404-1.536$ & 1.987 & $1.001-3.947$ \\
\hline \multicolumn{5}{|l|}{ Educational level (ref = "primary school or below") } \\
\hline Junior high school & 1.163 & $0.771-1.754$ & 0.812 & $0.535-1.232$ \\
\hline High school and secondary school & 1.144 & $0.707-1.851$ & 0.587 & $0.353-0.977$ \\
\hline College degree and above & 0.982 & $0.539-1.788$ & 0.355 & $0.176-0.718$ \\
\hline \multicolumn{5}{|l|}{ Occupational status (ref = "first category") } \\
\hline Second category & 1.056 & $0.716-1.557$ & 1.513 & $1.016-2.253$ \\
\hline Third category & 1.223 & $0.875-1.708$ & 1.026 & $0.710-1.483$ \\
\hline Marital status (ref = "married") & 1.150 & $0.751-1.761$ & 1.315 & $0.839-2.060$ \\
\hline \multicolumn{5}{|l|}{ Medical insurance (ref= "no") } \\
\hline Others & 0.632 & $0.363-1.100$ & 1.867 & $1.060-3.287$ \\
\hline Medical insurance for urban residents/new rural cooperative medical insurance & 0.918 & $0.623-1.353$ & 1.043 & $0.680-1.600$ \\
\hline Medical insurance for urban employees & 0.642 & $0.410-1.003$ & 1.245 & $0.768-2.020$ \\
\hline Smoking (ref = "yes") & 1.072 & $0.714-1.609$ & 0.975 & $0.640-1.485$ \\
\hline Drinking (ref = "yes") & 1.335 & $0.875-2.037$ & 0.902 & $0.584-1.394$ \\
\hline Family history of hypertension (ref= "no") & 0.736 & $0.515-1.051$ & 2.076 & $1.456-2.961$ \\
\hline \multicolumn{5}{|l|}{ Physical activity level (ref = "low level") } \\
\hline Moderate level & 0.564 & $0.352-0.905$ & 0.697 & $0.425-1.144$ \\
\hline High level & 0.583 & $0.375-0.907$ & 0.556 & $0.348-0.888$ \\
\hline
\end{tabular}

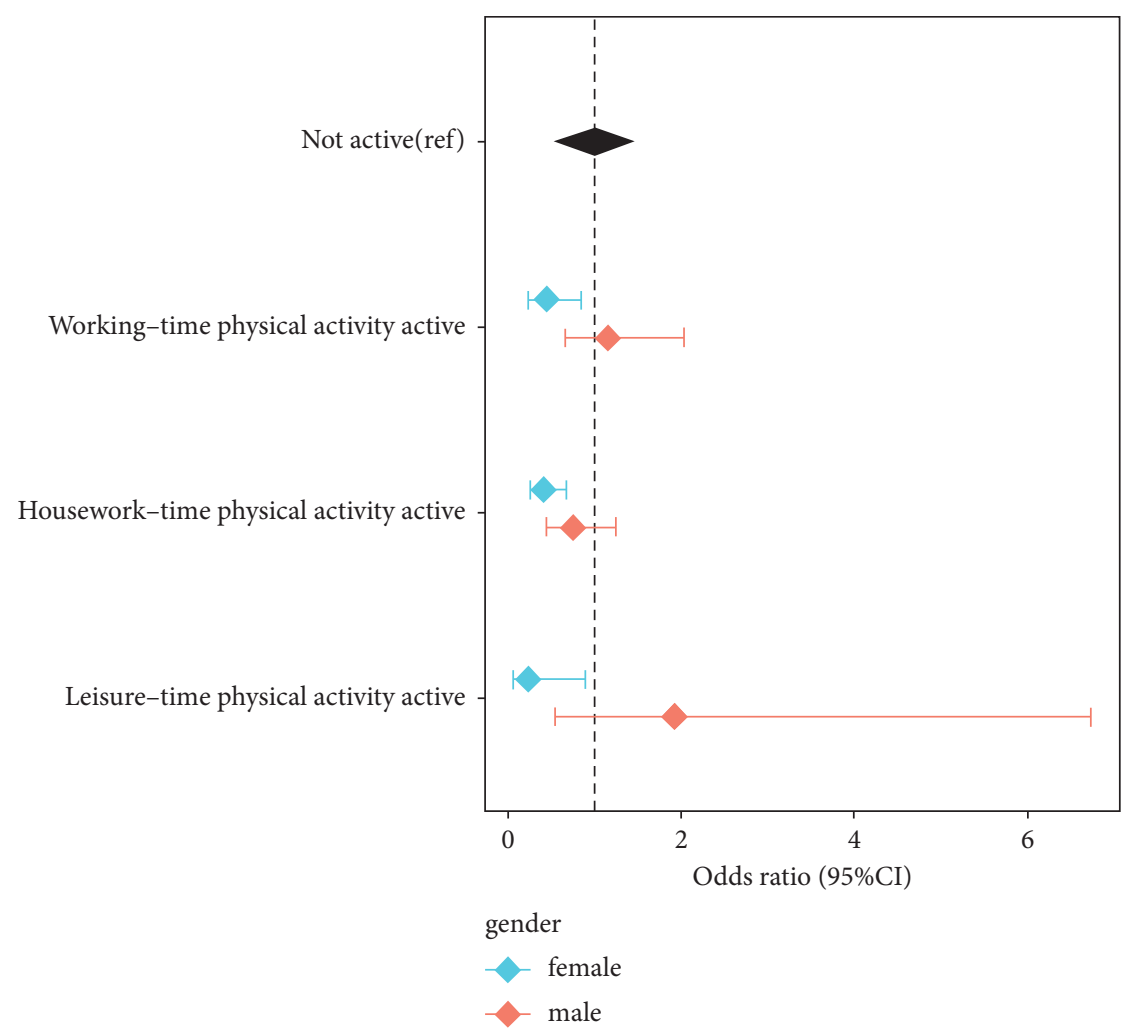

Figure 1: The impact of different types of physical activity on hypertension (adjusting for gender, age, occupational status, educational level, marital status, smoking, drinking, and family history of hypertension). 
TABLE 4: Multivariable analysis of association between overweight/obesity and hypertension.

\begin{tabular}{|c|c|c|}
\hline Variables & OR & $95 \% \mathrm{CI}$ \\
\hline Gender (ref = "male") & 0.557 & $0.382-0.812$ \\
\hline \multicolumn{3}{|l|}{ Age (years) $($ ref = “18-29”) } \\
\hline $30-44$ & 1.114 & $0.725-1.711$ \\
\hline $45-59$ & 1.553 & $0.997-2.418$ \\
\hline$\geq 60$ & 1.394 & $0.700-2.776$ \\
\hline \multicolumn{3}{|l|}{ Educational level (ref= "primary school or below") } \\
\hline Junior high school & 0.732 & $0.481-1.113$ \\
\hline High school and secondary school & 0.564 & $0.338-0.942$ \\
\hline College degree and above & 0.375 & $0.187-0.750$ \\
\hline \multicolumn{3}{|l|}{ Occupational status (ref = "first category") } \\
\hline Second category & 1.529 & $1.024-2.285$ \\
\hline Third category & 1.033 & $0.713-1.497$ \\
\hline Marital status (ref = "married") & 1.309 & $0.837-2.050$ \\
\hline \multicolumn{3}{|l|}{ Medical insurance (ref= "no") } \\
\hline Others & 1.847 & $1.032-3.306$ \\
\hline Medical insurance for urban residents/new rural cooperative medical insurance & 1.145 & $0.741-1.770$ \\
\hline Medical insurance for urban employees & 1.290 & $0.791-2.102$ \\
\hline Smoking (ref = "yes") & 0.956 & $0.628-1.456$ \\
\hline Drinking (ref = "yes") & 0.899 & $0.580-1.393$ \\
\hline Family history of hypertension (ref = "no") & 2.059 & $1.439-2.946$ \\
\hline Overweight or obesity (ref = "no") & 0.700 & $0.514-0.953$ \\
\hline
\end{tabular}

TABLE 5: The influence of family history of hypertension and overweight/obesity on hypertension.

\begin{tabular}{|c|c|c|c|}
\hline Variables & Number of illnesses & OR & $95 \% \mathrm{CI}$ \\
\hline Family history of hypertension and overweight/obesity & 62 & 1.000 & \\
\hline Family history of hypertension and not overweight/obesity & 114 & 1.183 & $0.615-2.276$ \\
\hline No family history of hypertension and not overweight/obesity & 425 & 0.644 & $0.366-1.133$ \\
\hline No family history of hypertension and overweight/obesity & 302 & 0.415 & $0.229-0.752$ \\
\hline
\end{tabular}

Adjusting for gender, age, occupational status, educational level, marital status, smoking, and drinking.

people in the present study, $83.0 \%$ had no family history of hypertension, and only $17.0 \%$ had a family history of hypertension. In addition, people with no hypertension family history with overweight/obesity were $58.5 \%$ less likely to have hypertension. Furthermore, the question of whether obesity is a mediator between physical activity and hypertension was analysed further. However, hypertension is affected by many factors and is more sensitive to physical activity and family history of hypertension. Obesity is a complication or a health outcome of numerous diseases, and it may exist as an interfering factor between hypertension and physical activity. The present study did not gather information on the study population's drug usage/medications, so it is possible that hypertensive participants took antihypertensive drugs prior to BP measurements. In addition, participants may change their modern dietary patterns based on roasted/smoked foods, instant foods, and fermented foods to prevent and control the development of hypertension after illness, but the study did not collect this information. These possibilities will affect the results [48]. Therefore, this study was not able to establish the relationship between obesity as a mediator affecting physical activity and hypertension. This relationship can be investigated in a follow-up study. Determining this relationship may elucidate the mechanism by which physical activity influences obesity and hypertension.
This study has several strengths and weaknesses. Given that the district is still in its early stages of urbanisation, the government should plan this area in such a way that is conducive to physical activity. This study provides additional evidence that links physical activity, obesity, and hypertension and lays a foundation for future research. Moreover, this study offers a hypothesis on the relationship between physical activity, obesity, and hypertension that can be tested in the future. However, this study was only a small crosssectional survey that excluded the determination of causality. Therefore, this study did not confirm the exact link between obesity and hypertension. In addition, the study did not gather other possible influencing factors, such as diet, medication, and salt intake, related to hypertension, which may have had an effect on the results. Finally, physical activity was obtained by self-reporting and questionnaires in the absence of professionals/objective instruments during measurements and recording. Hence, the data may have had inherent reporting bias. The objective and subjective physical activity levels of participants should be obtained with professional tools and questionnaires.

In the context of the "healthy city projects" of China, which attempt to shift the diagnosis and treatment of hypertension from "treatment-centred" to "health management-centred", prevention should be advocated, and 
healthy lifestyles should be promoted [49]. In this context, the present findings are relevant in the development of infrastructures in Pingshan District in such a way that promotes physical activity among the residents. In addition, the results also provide a basis for the health departments in formulating strategies for preventing and controlling hypertension. Health managers should strengthen communication with residents, help them change their lifestyles, monitor their conditions, and provide necessary information and suggestions to improve residents' self-management skills and better comply with health management suggestions [50]. The age structure of Pingshan District is relatively young, and the typical "healthy immigration phenomenon" may conceal the potential of exposure to more relevant risk factors in the population. The incidence of chronic diseases is higher in younger populations, and thus relevant studies must be conducted in this area.

\section{Data Availability}

The original data used to support the findings of this study are included within the article.

\section{Ethical Approval}

Ethical approval for the study was provided from the Ethics Committee of the School of Public Health, Wuhan University.

\section{Conflicts of Interest}

The authors declare that they have no conflicts of interest.

\section{Authors' Contributions}

Qianqian Dun and Yuliang Zou contributed to conceptualisation. Wanglin $\mathrm{Xu}$ and Ting Yu performed data curation. Qianqian Dun and Wanglin Xu conducted formal analysis and wrote the original draft. Maozhen $\mathrm{Fu}$ was responsible for funding acquisition. Xin Li and Yuliang Zou carried out investigation. Yating Du participated in methodology. Biao Zhang and Qiaomai Wang were involved in project administration. Yiting Duan was responsible for resources. Longwei Chen was responsible for software and visualisation. Xin Liu supervised the work. Nengjian $\mathrm{Wu}$ conducted validation. Justin B Moore reviewed and edited the paper. Qianqian Dun and Wanglin $\mathrm{Xu}$ contributed equally to this work and share first authorship.

\section{Acknowledgments}

This work was supported by more than one fund project, including National Natural Science Foundation of China (no. 51408442), Hubei Provincial Natural Science Foundation of China (no. 2018CFB570), and Research on Influencing Factors of Physical Activity Based on Ecological Model (no. 201602).

\section{References}

[1] World Health Organization | hypertension, 2020, https:// www.who.int/topics/hypertension/zh/.

[2] H. D. Bruce, Miskulin, and Z. Philip, "Epidemiology of hypertension in CKD," Advances in Chronic Kidney Disease, vol. 22, no. 2, pp. 88-95, 2015.

[3] Report on Nutrition and Chronic Diseases of Chinese Residents, 2015, http://www.nhc.gov.cn/xcs/s3574/201506/6b4c0f8 73c174ace9f57f11fd4f6f8d9.shtml.

[4] China 2010 Census Information, 2020, http://www.stats.gov. cn/tjsj/pcsj/rkpc/6rp/indexch.htm.

[5] H. Zhou, K. Wang, X. Zhou et al., "Prevalence and genderspecific influencing factors of hypertension among Chinese adults: a cross-sectional survey study in nanchang, China," International Journal of Environmental Research and Public Health, vol. 15, no. 2, 2018.

[6] J. D. Bundy and J. He, "Hypertension and related cardiovascular disease burden in China," Annals of Global Health, vol. 82, no. 2, pp. 227-233, 2016.

[7] N. K. Wenger, A. Arnold, C. N. Bairey Merz et al., "Hypertension across a woman's life cycle," Journal of the American College of Cardiology, vol. 71, no. 16, pp. 1797-1813, 2018.

[8] P. Rust and C. Ekmekcioglu, "Impact of salt intake on the pathogenesis and treatment of hypertension," Advances in Experimental Medicine and Biology, vol. 956, pp. 61-84, 2017.

[9] J. M. Dionne and J. T. Flynn, "Management of severe hypertension in the newborn," Archives of Disease in Childhood, vol. 102, no. 12, pp. 1176-1179, 2017.

[10] Y. Lu, R. Chen, J. Cai, Z. Huang, and H. Yuan, "The management of hypertension in women planning for pregnancy," British Medical Bulletin, vol. 128, no. 1, pp. 75-84, 2018.

[11] P. Perumareddi, "Prevention of hypertension related to cardiovascular disease," Primary Care: Clinics in Office Practice, vol. 46, no. 1, pp. 27-39, 2019.

[12] D. Ettehad, C. A. Emdin, A. Kiran et al., "Blood pressure lowering for prevention of cardiovascular disease and death: a systematic review and meta-analysis," The Lancet, vol. 387, no. 10022, pp. 957-967, 2016.

[13] R. Waken, L. de Las Fuentes, and D. C. Rao, "A review of the genetics of hypertension with a focus on gene-environment interactions," Current Hypertension Reports, vol. 19, no. 3, p. 23, 2017.

[14] Y. Kokubo, S. Padmanabhan, Y. Iwashima, K. Yamagishi, and A. Goto, "Gene and environmental interactions according to the components of lifestyle modifications in hypertension guidelines," Environmental Health and Preventive Medicine, vol. 24, no. 1, p. 19, 2019.

[15] P. G. Joseph, G. Pare, and S. S. Anand, "Exploring geneenvironment relationships in cardiovascular disease," Canadian Journal of Cardiology, vol. 29, no. 1, pp. 37-45, 2013.

[16] R. Kenneth, D. B. McLeroy, S. Allan, and K. Glanz, "An ecological perspective on health promotion programs," Health Education Quarterly, vol. 15, no. 4, pp. 351-377, 1988.

[17] J. F. Sallis, R. B. Cervero, W. Ascher, K. A. Henderson, M. K. Kraft, and J. Kerr, "An ecological approach to creating active living communities," Annual Review of Public Health, vol. 27, no. 1, pp. 297-322, 2006.

[18] E.-J. Rhee, J.-H. Cho, H. Kwon et al., "Association between abdominal obesity and increased risk for the development of hypertension regardless of physical activity: a nationwide population-based study," Journal of Clinical Hypertension, vol. 20, no. 10, pp. 1417-1426, 2018. 
[19] Y. You, W. Teng, J. Wang et al., "Hypertension and physical activity in middle-aged and older adults in China," Scientific Reports, vol. 8, no. 1, Article ID 16098, 2018.

[20] K. M. Diaz and D. Shimbo, "Physical activity and the prevention of hypertension," Current Hypertension Reports, vol. 15, no. 6, pp. 659-668, 2013.

[21] M. Börjesson, A. Onerup, S. Lundqvist, and B. Dahlöf, "Physical activity and exercise lower blood pressure in individuals with hypertension: narrative review of 27 RCTs," British Journal of Sports Medicine, vol. 50, no. 6, pp. 356-361, 2016.

[22] E. A. Bakker, X. Sui, A. G. Brellenthin, and D.-C. Lee, "Physical activity and fitness for the prevention of hypertension," Current Opinion in Cardiology, vol. 33, no. 4, pp. 394-401, 2018.

[23] Central People's Government of the People's Republic of China, 2020, http://www.gov.cn/shuju/2019-08/16/content_ 5421576.htm.

[24] C. J. Cao Yang, W. Cao Jian, and Q. Cheng, "Application of kish Grid sampling in world health survey (China survey)," Fudan University Journal of Medical Sciences, vol. 31, no. 3, pp. 307-310, 2004.

[25] C. L. Craig, A. L. Marshall, M. Sjöström et al., "International physical activity questionnaire: 12 -country reliability and validity," Medicine \& Science in Sports \& Exercise, vol. 35, no. 8, pp. 1381-1395, 2003.

[26] M. Fan, J. Lyun, and P. He, "Chinese guidelines for data processing and analysis concerning the International Physical Activity Questionnaire," Zhonghua Liu Xing Bing Xue Za Zhi, vol. 35, no. 8, pp. 961-964, 2014.

[27] J. Benítez-Porres, M. Delgado, and J. R. Ruiz, "Comparison of physical activity estimates using International Physical Activity Questionnaire (IPAQ) and accelerometry in fibromyalgia patients: the Al-Andalus study," Journal of Sports Sciences, vol. 31, no. 16, pp. 1741-1752, 2013.

[28] Association for Medical and Health Care, "Chinese guidelines for the management of hypertension chin," Journal of Cardiovascular Medicine, vol. 24, no. 1, pp. 24-56, 2018.

[29] I. Castro, G. Waclawovsky, and A. Marcadenti, "Nutrition and physical activity on hypertension: implication of current evidence and guidelines," Current Hypertension Reviews, vol. 11, no. 2, pp. 91-99, 2015.

[30] N. K. Adjei and T. Brand, "Investigating the associations between productive housework activities, sleep hours and selfreported health among elderly men and women in western industrialised countries," BMC Public Health, vol. 18, no. 1, p. 110, 2018.

[31] J. A. Chen, Y. B. Bai, Y. Jin, and L. Zhang, "Effect of different exercises on physical and mental health of menopausal women," Journal of Beijing Sport University, vol. 40, no. 2, pp. 62-67, 2017.

[32] Y. Q. Sang, X. H. Ma, and J. Shen, "Research progress of relationship between estrogen decrease and abdominal obesity and insulin resistance," Medical Recapitulate, vol. 19, no. 9, pp. 1660-1662, 2013.

[33] C. Jackson, G. C. Herber-Gast, and W. Brown, "Joint effects of physical activity and BMI on risk of hypertension in women: a longitudinal study," Journal of obesity, vol. 2014, Article ID 271532, 2014.

[34] X. L. Liu, Z. P. Zhuo, X. L. Yuan, J. P. Song, H. S. Chi, and J. Xu, "Opmaat tot een richtlijn," Bijzijn $X L$, vol. 8, no. 1 , pp. 21-23, 2015.

[35] Z. Su, "Analysis record of formal schooling of migrant workers in ningbo and educational status survey," Modern Marketing, vol. 3, pp. 74-75, 2014.
[36] W. E. Sadoh, A. E. Sadoh, and A. N. Onyiriuka, "Physical activity, body mass index and blood pressure in primary school pupils attending private schools," African Health Sciences, vol. 16, no. 4, pp. 947-953, 2016.

[37] X. Díaz-Martínez, F. Petermann, A. M. Leiva et al., "No cumplir con las recomendaciones de actividad física se asocia a mayores niveles de obesidad, diabetes, hipertensión y síndrome metabólico en población chilena," Revista Medica de Chile, vol. 146, no. 5, pp. 585-595, 2018.

[38] J.-Y. Moon, T. Wang, T. Sofer et al., "Objectively measured physical activity, sedentary behavior, and genetic predisposition to obesity in U. S. Hispanics/latinos: results from the hispanic community health study/study of latinos (HCHS/ SOL)," Diabetes, vol. 66, no. 12, pp. 3001-3012, 2017.

[39] A. C. Montezano and R. M. Touyz, "Oxidative stress, Noxs, and hypertension: experimental evidence and clinical controversies," Annals of Medicine, vol. 44, no. Suppl 1, pp. S2-S16, 2012.

[40] A. Virdis, A. Bacca, R. Colucci et al., "Endothelial dysfunction in small arteries of essential hypertensive patients," Hypertension, vol. 62, no. 2, pp. 337-344, 2013.

[41] P. M. Vanhoutte, H. Shimokawa, E. H. C. Tang, and M. Feletou, "Endothelial dysfunction and vascular disease," Acta Physiologica, vol. 196, no. 2, pp. 193-222, 2009.

[42] P. J. Millar, C. L. McGowan, V. A. Cornelissen, C. G. Araujo, and I. L. Swaine, "Evidence for the role of isometric exercise training in reducing blood pressure: potential mechanisms and future directions," Sports Medicine, vol. 44, no. 3, pp. 345-356, 2014.

[43] F. R. Roque, A. M. Briones, A. B. García-Redondo et al., "Aerobic exercise reduces oxidative stress and improves vascular changes of small mesenteric and coronary arteries in hypertension," British Journal of Pharmacology, vol. 168, no. 3, pp. 686-703, 2013.

[44] M. Korsager Larsen and V. V. Matchkov, "Hypertension and physical exercise: the role of oxidative stress," Medicina, vol. 52, no. 1, pp. 19-27, 2016.

[45] K. Briviba, B. Watzl, K. Nickel et al., "A half-marathon and a marathon run induce oxidative DNA damage, reduce antioxidant capacity to protect DNA against damage and modify immune function in hobby runners," Redox Report, vol. 10, no. 6, pp. 325-331, 2005.

[46] R. N. Teixeira, G. Dos Santos Leite, R. Gorjao et al., "Immune and inflammatory response in atopic elite endurance athletes," International Journal of Sports Medicine, vol. 39, no. 9, pp. 720-725, 2018.

[47] J. J. Fu, W. W. Wu, J. Gao, Y. D. Wang, Y. Tu, and Y. P. Shen, "Interactive effect of family hypertension history and overweight/obesity on hypertension in an occupational population," Chinese Journal of Public Health, vol. 35, no. 10, pp. 1236-1239, 2019.

[48] Z. Shi, K. Papier, V. Yiengprugsawan, M. Kelly, S.-A. Seubsman, and A. C. Sleigh, "Dietary patterns associated with hypertension risk among adults in Thailand: 8-year findings from the Thai cohort study," Public Health Nutrition, vol. 22, no. 2, pp. 307-313, 2019.

[49] Y. X. Sun, G. Z. Sun, and C. Wang, "Developing the system of "Internet+" hypertension under the guidance of "Healthy China 2030"," Chinese Journal of Cardiovascular Research, vol. 18, no. 5, pp. 385-387, 2020.

[50] M. C. Marco, A. Ambrogio, C. Francesca et al., "Feasibility and effectiveness of a disease and care management model in the primary health care system for patients with heart failure and diabetes," Vascular Health and Risk Management, vol. 6, pp. 297-305, 2010. 